\title{
NURSING CARE MANAGEMENT FOR WOMEN WITH BREAST CANCER IN PALLIATIVE CHEMOTHERAPY ${ }^{1}$
}

\author{
Juliana Dias Cirilo², Marcelle Miranda da Silva3a, Patrícia dos Santos Claro Fuly4, Marléa Chagas Moreira
}

\footnotetext{
${ }^{1}$ Article extracted from the thesis - A gerência do cuidado de enfermagem à paciente com câncer de mama avançado em quimioterapia paliativa, presented at Programa de Pós-Graduação, Escola de Enfermagem Anna Nery (EEAN), Universidade Federal do Rio de Janeiro (UFRJ), in 2015.

${ }^{2}$ M.Sc. in Nursing, EEAN/UFRJ. Rio de Janeiro, Rio de Janeiro, Brazil. E-mail: juli.cirilo@gmail.com

${ }^{3}$ Ph.D. in Nursing. Professor, EEAN/UFRJ. Rio de Janeiro, Rio de Janeiro, Brazil. E-mail: marcellemsufrj@gmail.com

${ }^{4}$ Ph.D. in Nursing. Professor, Escola de Enfermagem Aurora Afonso Costa, Universidade Federal Fluminense. Rio de Janeiro, Rio de Janeiro, Brazil. E-mail: claropatricia@yahoo.com.br

${ }^{5}$ Ph.D. in Nursing. Professor, EEAN/UFRJ. Rio de Janeiro, Rio de Janeiro, Brazil. E-mail: marleachagas@gmail.com
}

\begin{abstract}
The objective was to understand and to analyze the management of nursing care for women with breast cancer in palliative chemotherapy. This was an exploratory and qualitative study, which used the Grounded Theory. Eight nurses and ten patients of one of the units of the National Cancer Institute, Rio de Janeiro, Brazil, were interviewed. Data analysis showed five conceptual categories. The categories that represent the object of this study were: managing care during nursing consultation; pointing out the difficulties in carrying out nursing care management; listing administrative strategies to better manage care. Faced with the decision to administer palliative chemotherapy, nurses should pay attention to the need for care that women may present. Nurses play an important role in managing care, and contribute to a closer look at the recognition of such needs, prioritizing the quality of life.
\end{abstract}

DESCRIPTORS: Oncology nursing. Breast neoplasms. Antineoplastic agents. Management.

\section{A GERÊNCIA DO CUIDADO DE ENFERMAGEM À MULHER COM CÂNCER DE MAMA EM QUIMIOTERAPIA PALIATIVA}

RESUMO: Objetivou-se compreender e analisar a gerência do cuidado de enfermagem à mulher com câncer de mama em quimioterapia paliativa. Estudo exploratório, qualitativo, que utilizou a Teoria Fundamentada nos Dados. Foram entrevistados oito enfermeiras e dez pacientes de uma das unidades do Instituto Nacional de Câncer, Rio de Janeiro, Brasil. A análise dos dados evidenciou cinco categorias conceituais. As categorias que representam o objeto de composição deste estudo foram: Gerenciando o cuidado no momento da consulta de enfermagem; Apontando as dificuldades na realização da gerência do cuidado de enfermagem; e Elencando estratégias administrativas para melhor gerenciar o cuidado. Diante da decisão em realizar a quimioterapia paliativa, deve-se atentar para as necessidades de cuidado que a mulher pode apresentar. O enfermeiro tem importante participação ao gerenciar o cuidado, contribuindo para um olhar mais apurado quanto ao reconhecimento de tais necessidades, priorizando a qualidade de vida.

DESCRITORES: Enfermagem oncológica. Câncer de mama. Antineoplásicos. Gerência.

\section{LA GESTIÓN DE LOS CUIDADOS DE ENFERMERÍA A LA MUJER CON CÁNCER DE MAMA EN FASE DE QUIMIOTERAPIA PALIATIVA}

\begin{abstract}
RESUMEN: El objetivo fue conocer y analizar la gestión de los cuidados de Enfermería para las mujeres con cáncer de mama en fase de quimioterapia paliativa. Estudio exploratorio, cualitativo, que utilizó la teoría fundamentada en los datos. Ocho enfermeras y diez pacientes fueron entrevistadas en el Instituto Nacional del Cáncer, Rio de Janeiro, Brasil. El análisis de los datos mostró cinco categorías conceptuales. Las categorías que representan la composición del objeto de este estudio fueron: La gestión de la atención de Enfermería en la consulta; Señalando las dificultades para llevar a cabo la gestión de los cuidados de enfermería; Mostrando las estrategias administrativas para gestionar el cuidado. Ante la decisión de hacer la quimioterapia paliativa, se debe prestar atención a las necesidades de las mujeres, y la enfermera tiene un papel importante en la gestión de la atención, lo que contribuye a una mirada más próxima en el reconocimiento de tales necesidades, priorizando calidad de vida.
\end{abstract}

DESCRIPTORES: Enfermería oncológica. Neoplasias de la mama. Antineoplásicos. Gerencia. 


\section{INTRODUCTION}

Breast cancer is the most common cancer affecting women, representing $23 \%$ of all types of cancer incidents in the world. In 2014, 57,120 new cases of this disease were expected to be diagnosed in Brazil. ${ }^{1}$ Although there are several methods of treatment for breast cancer, many cases are beyond therapeutic healing possibilities. Altogether, it is estimated that $50 \%$ of cancer patients do not get cured. $^{2}$

Some authors discuss the use of palliative chemotherapy as an additional resource for advanced breast cancer control. However, unnecessary use of chemotherapy may worsen the clinical picture of women, due to the undesirable toxicities and adverse reactions related to this kind of treatment. ${ }^{2-5}$

In the face of the decision to undergo palliative chemotherapy, one must be attentive to the need for care that the patient may present. The nurse is the professional directly dealing with women and their families, being responsible for the administration of the chemotherapeutic agents. Nursing consultation is an effective strategy on an outpatient basis, as it favors the cultivation of a supportive interpersonal relationship, in which management of nursing care implies recognizing and meeting the needs of both patients and families. ${ }^{6}$

The present study aimed to understand and analyze the management of nursing care for women with breast cancer in palliative chemotherapy.

The study is justified by the following aspects: the situation of cancer in the context of health and its high rates of morbidity and mortality; the need for discussion regarding a clinical decision to indicate palliative chemotherapy in advanced cases; its impact on women's lives, which may call for multiple care needs; and the demands for professional skills in keeping with public health policies.

\section{METHOD}

This was an exploratory study with a qualitative approach, which used the Grounded Theory and followed the approach of full conceptual description. ${ }^{7}$

Data collection and analysis took place simultaneously, with the analysis being structured by open, axial and selective encodings. To contextualize the central phenomenon, as well as to define and refine the theoretical matrix, the paradigmatic model was used. Its elements are related to two fundamental aspects, structural conditions and the process. The first comprises the causal connections, the context and the conditions involved; the second covers the action-interaction strategies and their consequences. ${ }^{7}$

The investigation of the central phenomenon included the contribution from different participants and was comprised of two distinct sample groups. This is derived from the concept of theoretical sampling, which allows the researcher to search for their data in places or through testimony that are believed to hold some knowledge about the reality of the situation. In this study, the groups involved in the research process were the nurses and patients.

This study involved eight nurses and ten patients, who met the following inclusion criteria, being a nurse employed by the institution with a minimum experience of six months in chemotherapy treatment for patients with cancer. The inclusion criteria for the patient were: being a woman with advanced breast cancer, undergoing palliative chemotherapy, above 18 years of age and with cognitive abilities not affected. The exclusion criteria were: nurses on leave or vacation during the data collection period, and in the case of patients, women who did not undergo or who had any problems related to the treatment, such as discomfort or other adverse reactions. The inclusion of patients was performed through consultation with nurses and medical records.

All subjects agreed to participate in the study and signed an informed consent form, respecting the ethical aspects of the National Health Council resolution no 466/2012. The study was approved by the Etichal Research Committee of Escola de Enfermagem Anna Nery (EEAN), as the proponent institution, and of the Instituto Nacional do Câncer (INCA), as a co-participant institution. The study was approved on 12/18/2013, under protocol no. 468,478 . It is noteworthy that the composition of the second sample group followed the submission of an Amendment, on 06/24/2014, under protocol no. 698,923 .

The data were collected in the outpatient clinic for chemotherapy of the Cancer Hospital III (HC-III), one of the care units of INCA, in the city of Rio de Janeiro, Brazil. The HC-III specializes in the treatment of breast cancer and has been accredited as an Oncology High Complexity Center (CACON). ${ }^{8}$

Data collection took place between January and August 2014, through semi-structured interviews. The guide for nurses contained the following questions: What is your vision about nursing care management for patients with breast cancer in pal- 
liative chemotherapy? How do you manage the care of this patient? For patients, the questions were: Has your life changed after starting chemotherapy? In what ways? What were or have been the main problems? Who helps you the most? How does the nurse help you in each visit? What do you think could be done to help? Do you think you have a good level of understanding of this treatment? How has the nurse helped with what you know? Do you communicate well with the nurse?

The second sample group was guided by the hypothesis: in managing care, nurses seek to meet the needs of women with breast cancer through active listening and considering the particularities inherent to chemotherapy as a proposed palliative therapy.

The interviews, conducted individually, were recorded on a digital device, and subsequently transcribed in full, identified by alphanumeric codes.

Data analysis was conducted as follows: development of microanalysis line of raw data, that generated 1,496 preliminary codes; grouping of these codes, by similarity, in more abstract concepts, creating 18 conceptual codes, which evolved into five categories and 13 subcategories according to their level of complexity; and application of the paradigmatic model, taken in relation to the data, in order to organize them and configure the central phenomenon.

The discussion of data was performed from the critical position of the authors in view of the results and based on review of the literature.

\section{RESULTS}

The nurses presented a mathematical average of 15 years as the time of professional experience in the area of Oncology. With respect to the age group of the patients, one was in the age group between 20 to 30 years, two were between 31 and 40 years, six were between 41 to 50 years and one was between 51 to 60 years of age.

The five categories focused on the following central phenomenon; the nurses manage care for women with advanced breast cancer in palliative chemotherapy employing steps of the nursing process. Such care is provided especially at the time of the nursing consultation, which is guided by the needs of the patients. The patient is considered as a whole as she experienced this phase of the disease. The nurses assume some precepts of palliative care, and face relational, conceptual and structural problems.
Given the relevance and importance of the management of nursing care in the context investigated, the following categories have been selected for this study: managing care at the time of the nursing consultation; pointing out the difficulties in carrying out nursing care management; listing administrative strategies to better manage care. Such categories were qualified to occupy the positions of causal conditions, intervening conditions and action-interaction strategies, respectively, in accordance with the paradigmatic model employed.

\section{Managing care at the time of the nursing consultation}

This category is made up of four subcategories.

The subcategory 'Valuing the nursing consultation' highlights the importance of the nursing consultation, conducted upon the patient's admission at the outpatient chemotherapy clinic, The consultation contributes to the survey and consequent care of the patient's needs individually and in context. The nursing consultation is crucial, since [...] it is the first contact with the patient; and is the basis from where to start the management of care. The care is monitored, considering patients' needs here and at home. At that moment it is often realized that women arrive already as palliative (N1).

Women also valued this time, I went through nursing consultation twice. The nurses explain well, clear all doubts, all the details that really only nursing clarifies (P1).

The subcategory 'Applying the nursing process highlights the steps of the nursing process applied during the consultation, with emphasis on the taxonomy used in the diagnoses and nursing interventions: International Classification for Nursing Practice (ICNP). In this process, [...] Firstly, we identify the problems presented by the patient or what we can observe and, so, we plan the assistance, and follow the guidelines of the ICNP (N3).

It is from the application of the steps of the nursing process that nurses are instrumentalized, being able to list priorities, aiming at the optimization of time and quality of care.

Taking into account the time available to help, and all the logistics that we have, I see the priorities. What is more important to the patient at that time. I often notice that she has a difficulty in walking, but is also demonstrating pain. So, I'm going to focus on the pain. If I can minimize or even heal this pain, then I deal with the walking issue (N3).

The main nursing diagnoses were [...] fatigue, decreased appetite, nausea and vomiting, impaired physi- 
cal mobility, especially when the patient has bone metastasis, which is also very common [...]. Another important problem is the lack of intravenous access, compromised, because not all patients have central venous catheter, so if she has had a curative chemotherapy and is returning now to palliation, the veins may be much worse [...] (N2).

In the subcategory 'Highlighting the importance of communication', the importance of communication between nurses, patients and family members is emphasized to facilitate the understanding of the information about the proposal of treatment and the creation of bonds of trust. For that, you need to talk to the patient. I always explain: 'look, I'm going to talk about chemotherapy and I'm going to explain everything that will happen, but first I want to know what the doctor said. What did he explain about chemotherapy? So, I seek to have the sense of what she knows, because they often arrive without much knowledge. Then I explain everything, speak all about chemotherapy, its purpose and such. We say: 'Chemotherapy is to control your disease'. How the chemotherapy acts and hence I explain step by step what she might have and how to handle it [...] (N1).

It is worth noting the sensitivity of the nurse in seeking to understand what the patient wants to know at the time of consultation, since many women bring with them feelings of denial, depriving themselves of information about their situation as a defense mechanism.

Sometimes I would rather not know much. I know, I know what it's about, the thing is to be as I am and go on. I would rather leave some things behind (P2).

Generally, in the context investigated, the nurses deal, with a clientele with low to medium level of schooling, which influences a lot. So, it is complicated, and the nurse must to have insight as to what the patient knows, and what she is able to pick up, because there is a whole emotional issue in knowing that it is palliative (N4).

The importance of the nurse in the life of the patient at this time was observed in the interviews. It became clear that, because of the bonds created, the professional closest to the patient and their families is the nurse.

The patient chooses someone as a reference in the hospital and this is usually the nurse. Because we have more contact with them [...]. She leaves the doctor's appointment and comes after you, because she wants to hear from you that what she will take is right. So this is priceless (N8).

This reality is reinforced in the testimony of a patient: [...] I cleared more doubts with the nurses than with the doctors themselves. I think you get more connected, more used to them, like a colleague. Then you can, sometimes, ask them things you won't you ask the doctor (P6).

In the category 'Caring fully, seeking the autonomy of the patient', there is a need for nurses to lead the nursing consultation in such a way that women understand the importance of enjoying their days in the best possible way and are able to adhere to treatment. The nurses see to it that the "chemotherapy factor" does not hinder a patient's welfare and quality of life.

It's not the cancer, not the breast, not the tumor itself. They are human being and have needs. We have to take into account everything involved. There are the issues of family, children, possible pregnancy, work, college, and we try to also try to adapt in the face of our caring situation here (N4).

\section{Pointing out the difficulties in implementing the management of nursing care}

This category is made up of four subcategories.

In the subcategory 'Presenting the situation of cancer', although there are several treatments for breast cancer and measures for early diagnosis, many patients are faced with palliation. It was observed in the testimonies that most women who come to the sector to start treatment are already beyond therapeutic possibilities for healing.

Look, it's very sad, because media says, all the time, there is cure to breast cancer. I know it's curable when diagnosed early, but you see, in this condition, about $10 \%$ of patients you treat actually has a chance of cure, the rest is all palliative, and you have little to offer (N3).

Because of the large number of patients in the outpatient clinic of HCIII, national reference, it requires a greater coefficient of professionals to take care of these women, in addition to a more suitable physical structure. However, as might be seen in interviews, the human and physical resources available in this service are not appropriate, which may influence the quality of the assistance provided.

[...] the downside is that, sometimes, the workload is so high that everything ends up being hectic. I think it sometimes hampers care, making it a little more superficial. You want to chat, evolve, talk to the patient, but sometimes ends up doing everything faster [...]. O volume de trabalho [...], eu não sei, acho que não tem jeito, entra paciente mesmo, e a gente está sempre tentando ajustar a agenda, mas acho que isso não tem muita solução (N1).

In the subcategory 'Reporting the deficits in service', the deficits in the sector are taken into account, which can have direct consequences on the 
quality of nursing care, a patient's wait time for administration of chemotherapy and the quality of life of the professionals. The latter, in addition to not being able to offer the assistance desired, suffer because of lack of time for themselves. apart from attacks from escorts, or even from patients themselves. We have suffered verbal and almost physical assaults here, and because of this, there were some changes in relation to their staying here [...] (N8).

In the context investigated there are, deficits not only of human resources, but also physical. This structure does not bear so much customer service. We sometimes use the wheelchair and the emergency stretcher. And we are in a national reference hospital [...]. There are ten chairs, and we have grown a lot. We have patients with anaphylactic reaction who end up occupying the chair for longer than we anticipated [...] (N2).

In addition to the structural problems and human resource deficits, there is great difficulty for the patients in scheduling examinations that, even if they are urgent, take months to be scheduled. This fact may delay the confirmation of a diagnosis and, consequently, the beginning of the appropriate treatment.

First problem was that it was too complicated to get into here, but then I was well attended. And here everything is quite time-consuming, the tests are very time-consuming. Also, I think that this hinders the treatment. You are going to schedule an urgent test and then it is scheduled for within a month, two months. So it is complicated, but other than that, I have no further complaints (P1).

The subcategory 'Reporting daily problems in the flow of care' shows the current difficulty in organizing the flow of assistance and specific requirements with respect to the necessary time needed for each chemotherapy protocol.

The difficulty in structuring the agenda and its respective timetables is related not only to the high number of patients needing to undergo chemotherapy, but mainly to the possible fittings that may occur during the course of the day. Employees strive to meet the high number of patients, while patients suffer hours of waiting.

Then, you come here, you sometimes have to spend the whole day here, you may not always have a time estimation, there are times in which you arrive here at six, seven in the morning, because you still have the exams, and leaves at five in the afternoon. I mean, it is emotionally challenging (P9).

The subcategory 'Facing emotional difficulties in dealing with this profile of customers', showed that even with years of experience, some nurses have trouble dealing with palliation. Many suffer from the situation of young patients. Empathizing with each patient can trigger feelings of sadness.

That is awful! Until today I do not deal well with this, I get sad, get help getting involved. When the patient gets out of here, I realize it is palliative, I imagine she is no longer alive. Sometimes I check if she was admitted and pay a visit, because I like to create a bond. It is very sad arriving at the hospital at such an advanced stage, sometimes so young, even younger than me, having small children [...]. And you end up putting yourself in that person's place. I find it really sad watching a death sentence before your eyes (N7).

The young ages of women is currently a characteristic observed by nurses, which arouses feelings of vulnerability and affects them emotionally.

Nowadays, the age range of women with breast cancer is lower [...]. Today, we see young women who have not married, had no children or mothers of young children. So, when it comes to the issue of palliation there is a very big shock, because you know it is a point of no return [...] (N4).

\section{Listing strategies to better manage the care}

This category is made up of a subcategory: conducting a screening to confirm the patient's condition for undergoing chemotherapy that day. This always happens before a new cycle, and comprises an administrative strategy.

In this case, this subsequent query is what we call screening. It is when the patient returns for the second time for the treatment and here we do a kind of 'checklist': if she had a fever, has any infection, any injury. At that moment we verify whether she is able to undergo chemotherapy. Obviously, we are not the ones cancelling the chemotherapy, but according to what we observe, examine and diagnose, we can bring this problem to the doctor and he will cancel it (N3).

\section{DISCUSSION}

Nursing care management includes all actions directly or indirectly related to the care of patients. The interviews of both sample groups stressed the importance of the nursing consultation as a fundamental tool for the management of nursing care in outpatient chemotherapy, as well as a hard/soft technological strategy of care with great potential for solutions. ${ }^{9}$

The category 'Managing care at the time of nursing consultation' addresses the nurses' actions 
when managing nursing care for women. This considers the importance of the time dedicated to them in nursing consultation, which should be guided by the steps of the nursing process. Thus, one has the opportunity to clarify issues related to chemotherapy as a palliative proposal, often at the first moment of contact between the nurse and patient; as well as to educate women so that they are able to take care of themselves.

The consultation provides an opportunity for integration, creating bonds and establishing relationships of trust, which can promote adherence to treatment. Moreover, it is at the time of the nursing consultation that possible doubts and treatment protocols are clarified.

In the interviews, it was stressed that the taxonomy used in diagnosis and nursing interventions: ICNP, which was created by the International Council of Nurses, in 1989, was due to the need to standardize the practice of nursing on a global level. That being so, ICNP was used with the intention of being a global communication tool facilitating the documentation of nursing actions in a standardized way, in order to improve patient care. ${ }^{10}$

In the first stage of the nursing process, nurses identified listening as a primary approach in identifying and understanding the problems that may affect the patient at this stage. Communication is key, both in its verbal and non-verbal aspects, since there are implied needs that require some approach.

The nursing diagnosis will meet the evidence in the literature, for example, in the case of mastectomized women, those undergoing chemotherapy, or suffering from advanced cancer. Thus, the following diagnoses were considered: lack of consistence in exercises; impaired psychological well-being; altered eating and sleep patterns. Fatigue was also seen as an important side effect of chemotherapy, as it interferes with the performance of women's daily activities. ${ }^{11}$

The interventions took place in accordance with the problems presented by patients individually thus making them personal interventions and varying according to the needs for care at the time of consultation or at the time of the administration of chemotherapy. Considering the characteristics of ambulatory care, the need for proper orientation was emphasized, such as continuity of care in the household; encouraging the participation of the family; and the patients' personal care of themselves. These actions are possible when the nursing consultation is recognized as an opportunity for the exchange of knowledge, enabling patient safety and satisfaction. ${ }^{11-12}$
The bonds created during the nursing consultation facilitate the removal of doubts on the part of patients so that they feel at ease in sharing their difficulties. This allows the nurses to act in ways to help them cope during this time in the best way possible. Good communication between nursing staff, patients and families facilitates this approach for the quality of care. ${ }^{13}$

It is of extreme importance that women understand the proposals of the chemotherapy treatment that will be used. There is often a difficulty in understanding a palliative care plan, especially when the patient has a low educational level, which influences her own daily care at home. A study on the profile of patients in palliative chemotherapy found, with regard to education, that the largest number of patients claimed to have only an elementary school education $(58.5 \%)$, while only $10 \%$ of patients had higher education. ${ }^{14}$ This information corroborates the experience of the nurses, and is of particular concern given the importance of understanding on the part of women about the treatment and the guidelines they are given. In addition, according to the same study, a lower degree of schooling is associated with lower standards of health care.

Regarding the relationship between the nurse and the patient, it was clear in the testimonials that there was a greater identification between them, than in the doctor-patient relationship. This fact can be related to the fear of pestering the doctor with questions, trouble in understanding scientific terms, and unawareness of their own right to participate. Thus, nurses take on an important role, because they are closest to the patient They are responsible for providing information on the treatment, the specific drugs that will be used and the possible side effects of chemotherapy. In addition, it is necessary that the nurses help with the clearing of doubts and with dispelling fears and taboos about the disease and the chemotherapy treatment. For this reason, the nursing staff must be prepared to assist women in their entirety, comprised of humanized care and based on comprehensiveness. ${ }^{15}$

Some problems were cited by nurses and patients with regard to the implementation of the management and use of the services appropriately. Among the problems cited, the high demand made by patients proved to be an important reason for the work overload of nurses, as well as for the delay in daily care flow. This is because the number of patients arriving for care is a direct reflection of the epidemiological situation of cancer in Brazil. In the interviews, it was perceived that more and more 
patients arrive to receive care in the ambulatory clinic, a fact that raises the disease to a level of a major public health problem. It confirms breast cancer as the most common cancer among the female population, reinforcing the need for early detection and adequate treatment. ${ }^{1,16}$

The lack of a proper structure which can provide comfort to women, prevents them from relaxing at the time of the administration of chemotherapy. This is because the physical space of the sector is ill-suited to the needs of the patients, making it impossible for the presence of any escorts. In addition, the inadequate space also hinders the dynamics of nursing work. ${ }^{17}$

Despite such difficulties, the establishment of good relations contributed to greater tranquility in the environment as well as helped in overcoming barriers, bringing a certain lightness to the daily routine, which was recognized by the praise the patients expressed for the nurses. However, negative reviews were also evident, the main complaint reported by women being the delay in care, which creates stress in their relationship with their escorts.

Throughout the course of the disease, the family faces a sequence of stressors that can negatively influence their interpersonal relations, contributing to the crisis. These stressors were related to the duration of chemotherapy treatment, combined with other issues, such as the difficulties and delays in care, which explain the confusion between the escorts and the team. Verbal aggression by the escorts is naturally unjustifiable, but it is up to the nurses to understand and contextualize their difficulties and include the escorts as part of the whole disease/ treatment process. Such understanding contributes to harmony in the environment and minimizes suffering. ${ }^{18}$

This kind of problem is also related to the issue of the current workforce size in the face of an immoderate demand for health services. However, to achieve high-quality assistance, based on comprehensive, individualized, respectful and humane care, an adequate number of professionals is mandatory. Then the principles and guidelines of the public health system can be applied, especially with regard to completeness and equality. ${ }^{19}$

With respect to the barriers in the path of care, attention should be paid to the policy of the enrollment of new patients, since the interruption of this process may imply neglecting the population's needs. One should also think strategically about the organization of services regarding the completion of examinations, because a waiting list may change the course of the proposed treatment, result in late diagnosis of the disease and a reduction in survival, as well as generate stress and anxiety for women. On a larger scale, the obstacles should be considered in public health policies and in breast cancer control programmes. ${ }^{20}$

The problems mentioned in the testimonials in organizing the service flow related to the structuring the agenda, also causes stress. One can see that the provision of services is relatively low when compared to the great demand. Therefore, it is necessary to introduce changes leading to improvements in access to services.

The inadequate number of professionals to service the demand can lead to work overload, stress and physical and emotional distress, as reported in the comments of the nurses. These types of problems are intensified in the face of complex work contexts, particularly when experiencing the death and dying process.

From the nurses' comments, the difficulty in dealing with the situation of palliation and the prognosis of death was apparent. This occurs because as caretakers, they value life and have its maintenance as a goal. When seeing their patients suffer and face the possibility of death, feelings of sadness and frustration come to the surface, because they are unable to fulfill such a goal. The feeling of helplessness in the fight against breast cancer was clear in the interviews. This feeling arises due to professional training, which is directed at the maintenance of life, but often lacks any preparation with coping with death. Thus, the feeling that the situation is lost, and that death will cease to be just a possibility to soon become a reality, makes nurses realize their limitations and start questioning their professional skills, and even their own lives. ${ }^{15}$

In the social profile of women affected by breast cancer, there are unusual cases among younger age groups, and as can be observed in the study, a minority of patients undergoing chemotherapy were younger. However, young patients with breast cancer are also a reality in the service and in world statistics. The problem is that, when compared to patients over 40 years of age, younger women usually have a worse prognosis. ${ }^{21}$

The other problem related to the entry of young patients in the service is the impact on care. In the testimonies, the difficulty in dealing with the palliative situation of young patients was noted. However, there is a need for team training, for health professionals must meet the needs of care of young patients with breast cancer. ${ }^{22}$ 
The category 'Listing administrative strategies to better manage the care', stressed that screening in subsequent services was important to check whether the patient could undergo chemotherapy the same day. This is an administrative strategy used by nurses to better organize care. This subsequent consultation serves as a means to avoid the interruption of chemotherapy after it is started. It prevents a chair from being occupied by a patient who cannot receive the medication, which generates delays in the following services. In addition, it also prevents discomfort for the patient, such as in the case of prior assessment of peripheral venous plexus, preventing her from suffering repeated puncture attempts if the possibility of carrying out this procedure has already been discarded.

At the time of the consultation, the nurse should be aware of the patient's complaints, identifying her needs for care in order to meet them in the best way possible and encourage self-care practices, related, especially to the control of adverse reactions and the promotion of quality of life.

However, the factors impeding the administration of chemotherapy on the same day, must be carefully administered, since the patient goes to the doctor's office hoping to receive the medicine, and when this does not happen, anxiety and fear may be triggered, related to the continuous manifestation of the disease.

Therefore, nurses must have the skills and knowledge to assess the clinical condition of the patient and together with the medical team, make decisions with regard to whether or not the administration of chemotherapy should be performed at that particular time, focusing on women's quality of life and the improvement of their general condition. ${ }^{23}$

\section{CONCLUSION}

The study showed results that represent the reality observed at the research setting, highlighting the importance of nurses in the management of care for patients with breast cancer in palliative chemotherapy, either by direct assistance at the time of nursing consultation and during the administration of chemotherapy, or indirectly, through the organization of the environment and the flow of care.

Nurses, by being closest to patients, have the opportunity to get to know their weaknesses and difficulties, as well as, by a sensitive approach and by using technical and scientific knowledge, to understand the extent to which the women are able to receive chemotherapy.
The problems presented for properly conducting the management of nursing care refer to the institutional difficulties related to the deficit of human, physical and structural resources and to the high demand of patients.

The authors presented as a limitation of this research the fact that it portrayed only the reality of one single context. The research requires future expansions, incorporating other professionals' perspectives.

Further advancement in research in order to investigate other realities is suggested as is the validation of the data and meeting the needs of women, so that their quality of life does not stop being a priority. This research could lead to the possibility of the early integration between oncology and palliative care, and thus facilitate the achievement of this goal.

\section{REFERENCES}

1. Ministério da Saúde (BR). Instituto Nacional de Câncer José Alencar Gomes da Silva, Coordenação Geral de Ações Estratégicas, Coordenação de Prevenção e Vigilância. Estimativa 2014: incidência de câncer no Brasil. Rio de Janeiro (RJ): INCA; 2014.

2. Ortiz JS. Quimioterapia en la fase final de la vida: ¿es compasiva? Med Clin. 2011; 136(8):343-4

3. Kadakia KC, Moynihan TJ, Smith TJ, Loprinzi CL. Palliative communications: addressing chemotherapy in patients with advanced cancer. Ann Oncol. 2012 Apr; 23 (Suppl 3):29-32.

4. Ng T, Chew L, Yap CW. A clinical decision support tool to predict survival in cancer patients beyond 120 days after palliative chemotherapy. J Palliat Med. 2012 Aug; 15 (8):863-9.

5. Van Bekkum ML, Van Munster BC, Thunnissen PL, Smorenburg $\mathrm{CH}$, Hamaker ME. Current palliative chemotherapy trials in the elderly neglect patientcentred outcome measures. J Geriatr Oncol. 2015; 6(1):15-22.

6. Silva MM, Silva JA, Esteves LO, Mesquita MGR, Stipp MAC, Duarte SCM. Perfil sociodemográfico e clínico de pessoas em tratamento quimioterápico: subsídios para o gerenciamento em enfermagem. Rev Eletr Enf [Internet]. 2013 Jul-Set [cited 2014 Out 13]; 15(3):70412. Available from: http://dx.doi.org/10.5216/ree. v15i3.18417

7. Strauss A, Corbin J. Pesquisa qualitativa: técnicas e procedimentos para o desenvolvimento de teoria fundamentada. $2^{\mathrm{a}}$ edição. Porto Alegre (RS): Artmed; 2008.

8. Brasil. Portaria $n^{\circ} 62$, de 11 de março de 2009. Diário Oficial da República Federativa do Brasil, 11 Mar 2009, Seção 1. 
9. Silva JP, Garanhani ML, Peres AM. Sistematização da assistência de enfermagem na graduação: um olhar sob o pensamento complexo. Rev Latino-Am Enfermagem. 2015; 23(1):59-66.

10. Conselho Internacional de Enfermeiros. Linhas de orientação para a elaboração de catálogos CIPE®. Genebra (CH): Edição Portuguesa - Ordem dos Enfermeiros; 2009.

11. Pisoni AC, Kolankiewicz ACB, Scarton J, Loro MM, Souza MM, Rosanelli CLSP. Dificuldades vivenciadas por mulheres em tratamento para o câncer de mama. Rev Pesq Cuid Fundam [Internet]. 2013 Jul-Set [cited 2014 Aug 8]; 5(3): Available from: http:/ / www.seer. unirio.br/index.php/cuidadofundamental/article/ view/2029

12. Oliveira SK, Queiroz APO, Matos DPM, Moura AF, Lima FET. Temas abordados na consulta de enfermagem: revisão integrativa da literatura. Rev Bras Enferm. 2012 Jan-Fev; 65(1):155-61.

13. Silva MM, Moreira MC, Leite JL, Erdmann AL. Analysis of nursing care and the participation of families in palliative care in cancer. Texto Contexto Enferm [Internet]. 2012 Jul-Set [cited 2014 Aug 8]; 21(3):658-66. Available from: http://www. scielo.br/scielo.php?script=sci_arttext\&pid=S010407072012000300022\&lng=en\&nrm $=$ iso\&tlng $=$ en

14. Souza RS, Simão DAS, Lima EDRP. Perfil sociodemográfico e clínico de pacientes atendidos em um serviço ambulatorial de quimioterapia paliativa em Belo Horizonte. Rev Min Enferm. 2012 Jan-Mar; 16(1):38-47.

15. Lima PC, Comassetto I, Faro ACM, Magalhães APN, Monteiro VGN, Silva PSG. O ser enfermeiro de uma central de quimioterapia frente à morte do paciente oncológico. Esc Anna Nery. 2014; 18(3):503-9.

16. Kluthcovsky ACGC, Faria TNP, Carneiro FH, Strona R. Câncer de mama feminino: análise da mortalidade no Brasil e regiões. Rev Assoc Med Bras. 2014; 60(4):387-93.

17. Gomes SFS, Santos MMMCC, Carolino ETMA. Riscos psicossociais no trabalho: estresse e estratégias de coping em enfermeiros em oncologia. Rev Latino-Am Enfermagem. 2013; 21(6):1282-9.

18. Nascimento NA, Castro DS, Bicudo SDS, Amorim MHC. Estratégias de enfrentamento de familiares de mulheres acometidas por câncer de mama. Cienc Cuid Saúde. 2011; 10(4):789-94.

19. Pinto IC, Marciliano CSM, Zacharias FCM, Stina APN, Passeri IAG, Bulgarelli AF. As práticas de enfermagem em um ambulatório na perspectiva da integralidade. Rev Latino-Am Enfermagem. 2012; 20(5):909-16.

20. Gonçalves LLC, Travassos GL, Almeida AM, Guimarães AMD'aN, Gois CFL. Barreiras na atenção em saúde ao câncer de mama: percepção de mulheres. Rev Esc Enferm USP. 2014; 48 (3):394-400.

21. Pinheiro AB, Lauter DS, Medeiros GC, Cardozo IR, Menezes LM, Souza RMB, et al. Câncer de mama em mulheres jovens: análise de 12.689 casos. Rev Bras Cancerol. 2013; 59(3):351-9.

22. Dolina JV, Bellato R, Araújo LFS. O adoecer e o morrer de mulher jovem com câncer de mama. Ciênc Saúde Coletiva. 2013; 19(8):2671-80.

23. Souza CA, Jericó MC, Perroca MG. Mensuração de carga de trabalho de enfermeiros em ambulatório de oncologia. Rev Esc Enferm USP. 2014; 48(1):97-103. 